\title{
Protein-Conjugated Quantum Dots for Detecting Trypsin and Trypsin Inhibitor Through Fluorescence Resonance Energy Transfer
}

\author{
Chi-Wei Liu and Huan-Tsung Chang*,a,b \\ ${ }^{a}$ Department of Chemistry, National Taiwan University, Taipei, Taiwan \\ ${ }^{b}$ Department of Natural Science Education, National Taitung University, Taitung, Taiwan
}

\begin{abstract}
We have developed quantum dot probes for detecting trypsin (Try) and trypsin inhibitor (TI) in aqueous solutions through fluorescence resonance energy transfer (FRET). Green-fluorescent CdTe quantum dots (QDs) served as the energy donors and rhodamine isothiocyanate (RITC) conjugated to bovine serum albumin (BSA-RITC) was the acceptor. By simply mixing the two fluorophores, FRET occurred when BSA-RITC bound to the CdTe QDs; as a result, the fluorescence intensity of the CdTe QDs at $520 \mathrm{~nm}$ decreased, while the fluorescence of RITC at $574 \mathrm{~nm}$ increased. When Try was used to digest BSA, the FRET efficiency decreased, allowing the detection of Try at concentrations as low as 110 $\mathrm{pM}$. In the presence of TI, the digestion activity of Try was inhibited. As a result, the fluorescence intensity ratio $I_{\mathrm{F} 574} / I_{\mathrm{F} 520}$ of the QD-BSA-RITC solutions in the presence of a constant amount of Try increased upon increasing the concentration of TI; good linearity $\left(\mathrm{R}^{2}=0.99\right)$ existed over the range $0.3-5.0 \mathrm{nM}$. The LOD for TI was $250 \mathrm{pM}$. This simple and costeffective probe was applied to determine the level of spiked TI $(1.0 \mathrm{nM})$ in urine samples; the recoveries $(95-110 \%)$ suggested low matrix interference and high sensitivity.
\end{abstract}

\section{INTRODUCTION}

Recently, quantum dots (QDs) have become interesting materials for sensing analytes of interest, mainly because of their unique optical properties [1-4]. QDs provide a number of advantages over organic dyes, including high photobleaching thresholds, size-dependent emission wavelengths when excited at a constant wavelength, and narrow signals in emission spectra. In addition, QDs provide the advantages of multivalency (many recognition sites in one QD) and high absorption coefficients (effective quencher). The potential use of QDs for cell labeling and pathogen detection has been recognized [5-7]. To further improve their sensitivity, fluorescence resonance energy transfer (FRET) between pairs of different QDs or pairs of QDs and organic dyes has been exploited in the analysis of biomolecules [816]. The efficiency of FRET between CdSe/ZnS QDs (donors) and commercialized rhodamine-peptide molecules (acceptors) has been used to determine collagenase activity in normal and cancerous breast cells [16]. When collagenase cleaved the linker, it induced the FRET to disappear and the fluorescence of the $\mathrm{CdSe} / \mathrm{ZnS}$ QDs to be regained. Under optimum conditions, this approach provided a limit of detection (LOD) for collagenase at a signal-to-noise ratio $(\mathrm{S} / \mathrm{N})$ of 3 of $0.5 \mu \mathrm{g} / \mathrm{mL}$. Because nonspecific adsorption tends to occur and the fluorescence properties of QDs are highly environment-sensitive, quenching due to the presence of salt, $\mathrm{pH}$ changes, and adsorbents are common for CdSe/ZnS QDs $[17,18]$. Preparation of $\mathrm{CdSe} / \mathrm{ZnS}$ QDs is tedious: it usually requires at least two steps and is conducted at high temperature [16]. Based on our experience, the batch-to-batch variation of the QYs for CdSe/ZnS QDs is high. In addition, ligand exchange reaction has to be carried out before/during

*Address correspondence to this author at the Department of Chemistry, National Taiwan University, Taipei, Taiwan; Tel/Fax: 011-886-2-33661171; E-mail: changht@ntu.edu.tw conducting bioconjugation, which usually results in decreases in fluorescence intensity.

The goal of this study was to develop a QD-FRET-based sensing technique for detecting trypsin (Try) and trypsin inhibitor (TI) in biological samples such as urine. TI is presently an important marker for ovarian, bladder, kidney, and renal cancers [19-21]. Conventionally, determination of the concentration of TI in biological samples, such as plasma and urine, is performed using radioimmunoassays or immunofluorometic assays [22, 23]. Although they are sensitive, these techniques suffer from high cost, matrix interference, and safety concerns. In our present FRET assay, greenfluorescent CdTe QDs served as energy donors and rhodamine isothiocyanate (RITC) bioconjugated with bovine serum albumin (BSA) acted as the acceptor. We carefully investigated the effects that BSA had on the stability of the CdTe QDs and the FRET efficiency between the CdTe QDs and BSA-RITC [2, 24-26]. The FRET efficiency was modulated upon the addition of Try, which allowed the detection of TI through its inhibition of the activity of Try digestion.

\section{MATERIALS AND METHODS}

Chemicals. Cadmium perchlorate, BSA, 3-mercaptopropionic acid (MPA), RITC, sodium borohydride, sodium hydroxide, tellurium powder, and Try were purchased from Sigma-Aldrich (Milwaukee, WI, USA). Sodium phosphate dibasic anhydrous and sodium phosphate monobasic monohydrate, which were used to prepare the phosphate buffer ( 5 $\mathrm{mM}, \mathrm{pH}$ 7.4), were obtained from JT Baker (Phillipsburg, NJ, USA). TI from chicken eggwhites was purchased from MP Biomedicals (Irvine, CA, USA). Agarose was obtained from BMA (Rockland, ME, USA).

Bioconjugation of BSA-RITC. A stock solution of RITC (10 mM) was prepared in DMSO. An aliquot of RITC solution $(10 \mathrm{mM}, 10 \mu \mathrm{L})$ was added to BSA solution (10 $\mu \mathrm{M}, 10 \mathrm{~mL})$, which had been prepared in sodium phosphate buffer (5.0 mM, pH 7.4), to give a final RITC-to-BSA molar 
ratio of $1: 1$. The mixture was stirred at ambient temperature overnight. A laboratory-made capillary electrophoresis (CE) system [27] was applied to confirm the bioconjugation of BSA-RITC. The solution of BSA-RITC was stored at $-4^{\circ} \mathrm{C}$ prior to use.

Synthesis and Characterization of CdTe QDs. Sodium borohydride $(0.08 \mathrm{~g})$ was reacted with tellurium powder $(0.127 \mathrm{~g})$ in water $(1.0 \mathrm{~mL})$ to produce sodium hydrogen telluride (NaHTe, $0.99 \mathrm{M})$. The NaHTe solution $(0.6 \mathrm{~mL})$ was then added to a $\mathrm{N}_{2}$-saturated mixture $(74.8 \mathrm{~mL} ; \mathrm{pH} 11.2)$ consisting of MPA $(3.8 \mathrm{mM})$ and $\mathrm{Cd}\left(\mathrm{ClO}_{4}\right)_{2}(16 \mathrm{mM})$ to give a final $\mathrm{Cd}^{2+} / \mathrm{MPA} / \mathrm{HTe}^{-}$molar ratio of $1: 2.4: 0.5$. The resulting mixture was heated at $96^{\circ} \mathrm{C}$ under reflux for $1 \mathrm{~h}$. The color of the solution changed from dark red to orangeyellow, indicating the formation of CdTe QDs that fluoresced at $520 \mathrm{~nm}$ when excited at $350 \mathrm{~nm}$. The UV-Vis absorption and fluorescence spectra of the as-prepared CdTe QDs were recorded using a double-beam UV-Vis spectrophotometer (Cintra 10e, GBC Scientific Equipment Pty Ltd, Dandenong, Victoria, Australia) and a fluorometer (AmincoBowman Series 2, ThermoSpectronic, Pitsford, NY, USA), respectively. The quantum yields (QYs) of the CdTe QDs were determined by using rhodamine $6 \mathrm{G}$ as the standard [28]. The sizes of the as-prepared CdTe were measured using a JSM-1200EX II (JEOL Ltd., Tokyo, Japan) transmission electron microscope (TEM). To confirm the contents of the elements of the as-prepared CdTe QDs, energy-dispersive Xray (EDX) spectroscopy measurements were conducted using a Philips Tecnai 20 G2 S-Twin microscope (Philips Ltd., Holland) that was operated at $200 \mathrm{kV}$. X-ray powder diffraction (XRD) patterns were recorded using $\mathrm{Cu} \mathrm{K} \alpha$ radiation (model: X'Pert Pro; PANalytical, Spectris plc, UK). The QDs were placed on quartz glasses prior to XRD measurements.

Preparation and Characterization of CdTe-BSARITC QDs. Aliquots $(1 \mathrm{~mL})$ of $5.0 \mathrm{mM}$ phosphate buffer solutions containing CdTe QDs $(0.3 \mu \mathrm{M})$ and BSA-RITC $(0.3-3.0 \mu \mathrm{M})$ were incubated in the dark for $1 \mathrm{~h}$ to form CdTe-BSA-RITC QDs. To characterize the resultant CdTeBSA-RITC QDs, fluorescence and TEM measurements were conducted as described above. When conducting electrophoresis using a laboratory-made system, the $\mathrm{CdTe}$ and $\mathrm{CdTe}-$ BSA-RITC QDs solutions $(20 \mu \mathrm{L})$ were loaded into different wells in an agarose gel and separated in $5.0 \mathrm{mM}$ sodium phosphate buffer $(\mathrm{pH}$ 7.4) for 10 min under a constant electric field $(-8.3 \mathrm{~V} / \mathrm{cm})$.

Detection of Try and TI. Analyses of Try and TI using CdTe-BSA-RITC QDs were performed in $5 \mathrm{mM}$ sodium phosphate buffer ( $\mathrm{pH} 7.4)$. Aliquots $(1 \mathrm{~mL})$ of solutions containing the probe (CdTe-BSA-RITC QDs, $30 \mathrm{nM}$ ) and various concentrations of Try $(0-25 \mathrm{nM})$ were incubated in the dark at $37^{\circ} \mathrm{C}$ for $3 \mathrm{~h}$. To monitor the digestion efficiency of Try, the solutions were subjected to fluorescence measurements. For the analysis of TI, aliquots $(1 \mathrm{~mL})$ of $5 \mathrm{mM}$ sodium phosphate solutions ( $\mathrm{pH}$ 7.4) containing constant concentrations of CdTe-BSA-RITC QDs (30 nM) and Try (10 $\mathrm{nM})$, and various amounts of TI $(0-25 \mathrm{nM})$ were incubated in the dark at $37^{\circ} \mathrm{C}$ for $3 \mathrm{~h}$. The fluorescence spectra of the solutions were then recorded.

Analysis of Urine Samples. Urine samples (500 $\mu \mathrm{L})$ from adult males were spiked with TI at final concentrations ranging from 0 to $10 \mathrm{nM}$ and then TI, as well as possible peptides and proteins, were collected by centrifugal filtration using a filter having a cutoff of $3 \mathrm{kDa}$. The collected materials were finally resuspended in $5 \mathrm{mM}$ sodium phosphate $(\mathrm{pH}$ 7.4); herein, these samples are known as the "collected sample solutions." Aliquots $(1 \mathrm{~mL})$ of solutions containing the probe (CdTe-BSA-RITC QDs, $30 \mathrm{nM})$, Try (10 nM), sodium phosphate $(5 \mathrm{mM}, \mathrm{pH} 7.4)$, and the collected sample solutions were mixed and incubated in the dark at $37^{\circ} \mathrm{C}$ for 3 $\mathrm{h}$ prior to fluorescence measurement. The recovery was calculated using an internal standard method, based on the linear plot of the ratio between the fluorescence intensities of the acceptor at $574 \mathrm{~nm}$ and the donor at $520 \mathrm{~nm}\left(I_{\mathrm{F} 574} / I_{\mathrm{F} 520}\right)$ against the standard TI concentration.

\section{RESULTS AND DISCUSSION}

Characterization of CdTe-BSA-RITC QDs. The presence of signals for the (111), (220), and (311) facets in the XRD and EDX spectra (not shown) confirm that the asprepared nanoparticles were cubic zinc blended CdTe QDs [29-32]. The QY of the CdTe QDs was 10\%, as determined through comparison with that of rhodamine 6G. The TEM images of the CdTe and CdTe-BSA-RITC QDs (Fig. $(\mathbf{1 A}, \mathbf{B})$, respectively) indicate that the two QDs had similar sizes (diameters of ca. 2.7 and $2.9 \mathrm{~nm}$, respectively) and were dispersed well. We used electrophoresis to separate the CdTe-BSA-RITC QDs from the CdTe QDs after derivatization with BSA-RITC (Fig. 1C).
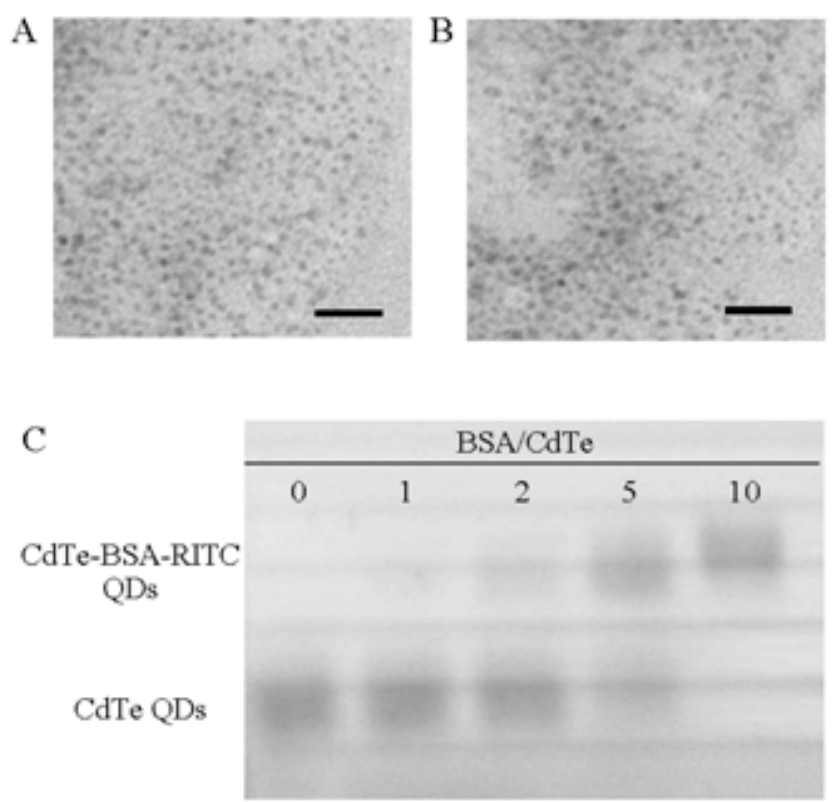

Fig. (1). TEM images of (A) CdTe QDs and (B) CdTe-BSA-RITC QDs; scale bars: $20 \mathrm{~nm}$. (C) Agarose gel electrophoresis image of CdTe and CdTe-BSA-RITC QDs that had been prepared by adding BSA-RITC to CdTe QDs $(0.3 \mu \mathrm{M})$ at various molar ratios at $25^{\circ} \mathrm{C}$. Separation was performed in $1.0 \%$ agarose for 10 min under a constant electric field $(-8.3 \mathrm{~V} / \mathrm{cm})$. The background electrolyte was 5.0 $\mathrm{mM}$ sodium phosphate buffer ( $\mathrm{pH}$ 7.4).

Upon increasing the $[\mathrm{BSA}] /[\mathrm{CdTe}$ QD] molar ratio, the fluorescence intensity of the band corresponding to the CdTe QDs became weaker, whereas the band for the CdTe-BSARITC QDs became stronger. At a [BSA]/[CdTe QDs] molar ratio of 10 , the band for the CdTe QDs disappeared, indicat- 
ing that almost all of the CdTe QDs had become bioconjugated with BSA-RITC. Our results agree well with those in the literature $[10,11]$. Because BSA-RITC has a higher molecular weight and a lower charge density than does MPA (capping agent) under our experimental conditions, the mobility of the CdTe QDs (capped with MPA) was higher than that of the CdTe-BSA-RITC QDs [12]. Both the CdTe and CdTe-BSA-RITC QDs migrated toward the anode, suggesting that these two sets of QDs possessed negative charges.

The fluorescence QY of CdTe QDs is very sensitive to the environment, including the $\mathrm{pH}$, ionic strength, and matrix species [29-32]. The changes in fluorescence of CdTe QDs are due mainly to variations in their surface properties. The fluorescence of CdTe QDs reaches its maximum at $\mathrm{pH}$ 6.0, but remains almost constant over the $\mathrm{pH}$ range 5.0-9.0 [30]. Fig. (2) exhibits the fluorescence spectra (excitation wavelength: $350 \mathrm{~nm}$ ) of BSA-RITC and the CdTe, CdTe-BSA, and CdTe-BSA-RITC QDs in $5 \mathrm{mM}$ sodium phosphate $(\mathrm{pH}$ 7.4). It is interesting to note that the fluorescence for the BSA-CdTe QDs was stronger (by ca. 2.2-fold) than that for the CdTe QDs. The reason for this increased fluorescence QY is the lower number of surface defects and the formation of a few double- and triple-dot aggregates induced by the conjugation of BSA [2]. Relative to CdTe, the BSA-CdTe QDs were more stable (at least 6 months) in aqueous solution at $4^{\circ} \mathrm{C}$. The fluorescence of the BSA-CdTe QDs remained almost constant in phosphate buffer ( $\mathrm{pH}$ 7.4) at ionic strengths up to $500 \mathrm{mM}$. Based on our own experience, protein-stabilized QDs are more stable in high-salt solution than are peptide-stabilized QDs. Because BSA-CdTe QDs are stable and highly fluorescent, 2-step preparation process for forming core-shell QDs is not required. We also note that our preparation method is simple and more biologically friendly than other methods $[16,32]$. Because the maximum excitation wavelength for RITC appears at $550 \mathrm{~nm}$, the fluorescence of BSA-RITC is quite weak when excited at 350 $\mathrm{nm}$. Upon increasing the $[\mathrm{BSA}] /[\mathrm{CdTe} \mathrm{QD}]$ ratio, the fluorescence at $520 \mathrm{~nm}$ (from CdTe QDs) decreased, while that at $574 \mathrm{~nm}$ (from RITC) increased. This result clearly indicates that FRET occurred between the CdTe QDs and RITC. We note that the FRET efficiency reached a plateau at a [BSA]/[CdTe QDs] ratio of 10, consistent with our electrophoretic results.

Temperature Effect. Although the fluorescence QY for the CdTe QDs remained almost constant over the temperature range $25-100^{\circ} \mathrm{C}$, we found that the temperature affected the QY of the CdTe-BSA QDs. The fluorescence at $520 \mathrm{~nm}$ increased ca. 1.8-fold when we increased the temperature from 25 to $80^{\circ} \mathrm{C}$, probably because the CdTe QDs surfaces were covered with BSA more completely at elevated temperatures, especially above $60^{\circ} \mathrm{C}$ (around the denaturation temperature of BSA). It has been reported loss of the $\alpha$-helix of BSA occurs to a great extent upon increasing the temperature $[24,33]$. We note that although BSA molecules contain at least 86 arginine and lysine residues that can be labelled with RITC, usually fewer than eight RITC units can be labeled per protein because of steric restrictions resulting from its tertiary structure [24, 33]. Thus, we suggest that changes in the BSA conformation on the CdTe QD surfaces play an important role. At higher temperatures, the exposed thiol residues arising from the cleavage of $\mathrm{S}-\mathrm{S}$ bonds in BSA are likely to further strengthen the interactions between BSA and the CdTe QDs. With a better coverage of the surface, fluorescence quenching due to surface adsorbents, especially those that are redox-active molecules, such as $\mathrm{O}_{2}$, is minimized. It is also important to note that the fluorescence of the CdTe-BSA and CdTe-BSA-RITC QDs was more stable after the BSA solutions had been treated at $80^{\circ} \mathrm{C}$ for $60 \mathrm{~min}$. To investigate the FRET efficiency between RITC and the CdTe QDs, we conducted fluorescence measurements of CdTe-BSA-RITC QD solutions at ambient temperature and pressure. The fluorescence intensity ratios $I_{\mathrm{F} 574} / I_{\mathrm{F} 520}$ increased almost linearly with increasing temperature and reached a plateau at a preparation temperature of $80^{\circ} \mathrm{C}$. With increasing temperature, the distance between RITC and the CdTe surface decreased as a result of more functional amino acid residues having been exposed. Increasing the temperature further $\left(>80^{\circ} \mathrm{C}\right)$ resulted in multilayers of BSA forming on the CdTe QD surfaces as a result of thermal aggregation of BSA molecules; this behavior led to decreases in the FRET efficiency. At $80^{\circ} \mathrm{C}$, the fluorescence of the CdTe QDs at $520 \mathrm{~nm}$ was quenched by BSA-RITC to a magnitude of ca. $74 \%$, while the fluorescence of BSA-RITC at $574 \mathrm{~nm}$ increased ca. 6.5-fold.

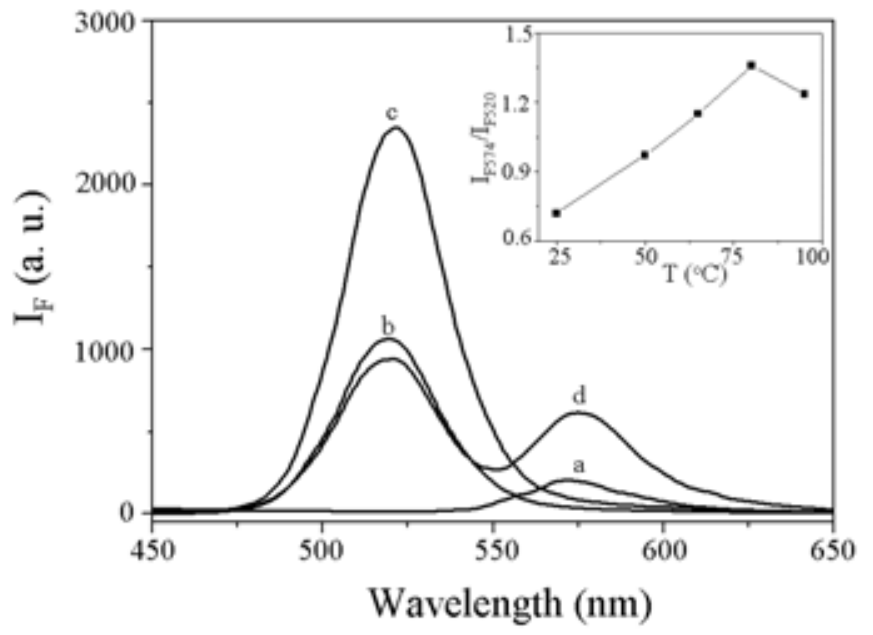

Fig. (2). Fluorescence spectra of (a) BSA-RITC (300 nM), (b) CdTe QDs (30 nM), (c) CdTe-BSA QDs (30 nM), and (d) CdTeBSA-RITC QDs $(30 \mathrm{nM})$ in $5 \mathrm{mM}$ sodium phosphate $(\mathrm{pH} \mathrm{7.4)}$ at $25^{\circ} \mathrm{C}$. Inset: Plot of $I_{\mathrm{F} 574} / I_{\mathrm{F} 520}$ of CdTe-BSA-RITC QDs as a function of the preparation temperature. The fluorescence intensities $\left(\mathrm{I}_{\mathrm{F}}\right)$ are plotted in arbitrary units (a.u.).

FRET Assay Mechanism. As indicated in Scheme 1, the emission wavelength of green-fluorescent CdTe QDs at 520 $\mathrm{nm}$ makes them serve as an energy donor for BSA-RITC (acceptor). The fluorescence intensity of the QDs at $520 \mathrm{~nm}$ decreased and the corresponding fluorescence of BSA-RITC at $574 \mathrm{~nm}$ increased through FRET. In the presence of Try, BSA molecules are digested to form small peptides. As a result, some of the peptides (with and without labeling with RITC) were released to the bulk solution causing the decreased FRET. In the other words, the fluorescence ratio $\left(I_{\mathrm{F} 574} / I_{\mathrm{F} 520}\right)$ of the CdTe-BSA-RITC QD solutions decreased upon increasing the concentration of Try. In the presence of TI, the digestion efficiency of Try toward BSA decreases upon increasing the concentration of TI. As a result, FRET between BSA-RITC and CdTe QDs is recovered. In other words, at constant concentrations of Try and the CdTe-BSA- 


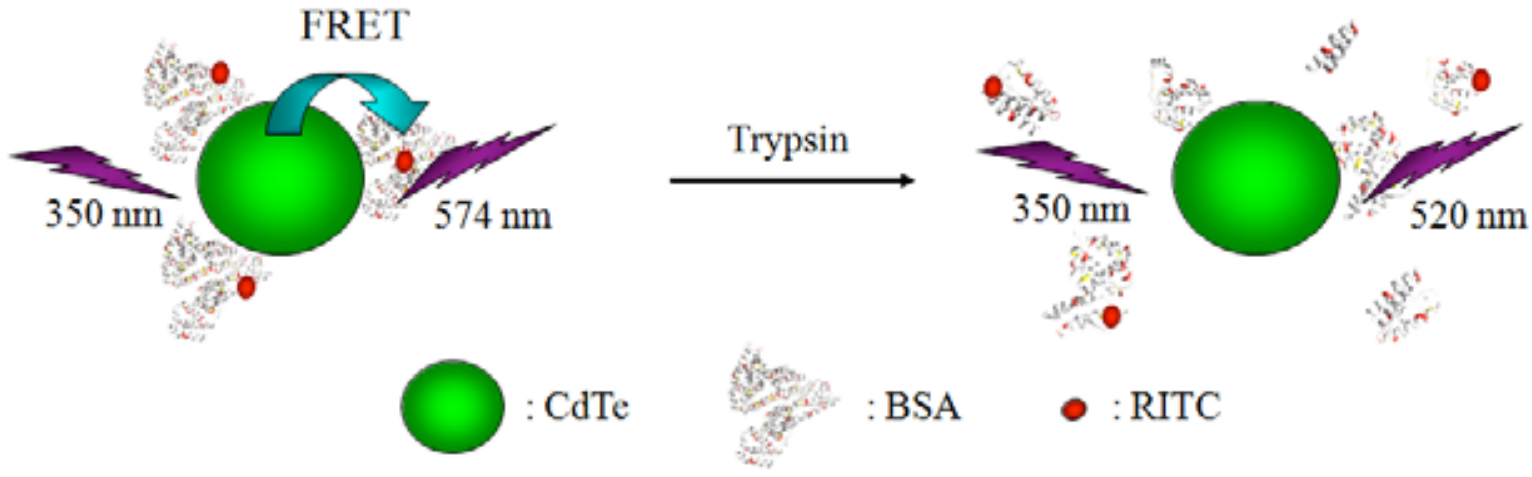

Scheme 1. FRET assay mechanism.

RITC QDs, the fluorescence ratio $\left(I_{\mathrm{F} 574} / I_{\mathrm{F} 520}\right)$ increased upon increasing the concentration of TI.

Analysis of Try and TI. Fig. (3A) displays fluorescence spectra of the CdTe-BSA-RITC QDs in the absence and presence of Try $(5.0 \mathrm{nM})$. In the presence of Try, the fluorescence of the CdTe-BSA-RITC QDs at $520 \mathrm{~nm}$ increased, while that at $574 \mathrm{~nm}$ decreased, upon increasing the incubation time (inset A). The reaction was almost complete $(90 \%)$ after $3 \mathrm{~h}$.

Thus, we conducted the subsequent experiments by setting the reaction time to $3 \mathrm{~h}$. In the course of digestion, the color of the fluorescence of the solution changed from orange to green (inset B). We note that the digestion efficiencies of Try toward BSA were similar when using the CdTeBSA-RITC QDs that had been prepared at 25 and $80^{\circ} \mathrm{C}$. The changes that occurred to the CdTe-BSA-RITC QDs upon Try digestion were further supported by the time-evolution fluorescence spectra. Inset $\mathrm{C}$ in Fig. (3A) displays relaxation curves for the fluorescence of the CdTe-BSA and CdTeBSA-RITC QDs and of the CdTe-BSA-RITC QDs in the presence of Try; their lifetimes were $22.5,13.8$, and $21.9 \mathrm{~ns}$, respectively. FRET between the CdTe QDs and RITC provided a relaxation pathway and, thus, the lifetime of the CdTe QDs decreased in the presence of BSA-RITC $[11,35]$. As indicated in Fig. (3B), the $I_{\mathrm{F} 574} / I_{\mathrm{F} 520}$ ratios of the CdTeBSA-RITC QDs decreased upon increasing the concentration of Try. A linear correlation $\left(\mathrm{R}^{2}=0.98\right)$ existed between the $I_{\mathrm{F} 574} / I_{\mathrm{F} 520}$ ratios and the concentration of Try over the range $0.20-5.0 \mathrm{nM}$. The $\mathrm{LOD}(\mathrm{S} / \mathrm{N}=3)$ for Try was $110 \mathrm{pM}$.

Competitive Assay. By taking advantage of the inhibitory effect of TI on the Try digestion of BSA [36], we detected TI by monitoring the CdTe-BSA-RITC QDs in the presence of Try. As described in Scheme 1, FRET occurred between the QDs and RITC to a greater extent in the presence of Try and TI than in the presence of Try alone. As indicated in Fig. (4), the $I_{\mathrm{F} 574} / I_{\mathrm{F} 520}$ ratios increased upon increasing the TI concentration. On the basis of the linear plot of the $I_{\mathrm{F} 574} / I_{\mathrm{F} 520}$ ratios over the TI concentration range 0.30 $5.0 \mathrm{nM}\left(\mathrm{R}^{2}=0.99\right)$, we estimated the $\operatorname{LOD}(\mathrm{S} / \mathrm{N}=3)$ for $\mathrm{TI}$ to be $250 \mathrm{pM}$. To further test the practicality of this present method, we conducted a similar experiment in the presence of $1.0 \mu \mathrm{M}$ BSA (i.e., at a concentration 1000 times higher than that of TI; the concentration of total proteins in urine is less than 1.0 $\mu \mathrm{M}$ [37]); we obtained a linear plot $\left(\mathrm{R}^{2}=0.98\right)$
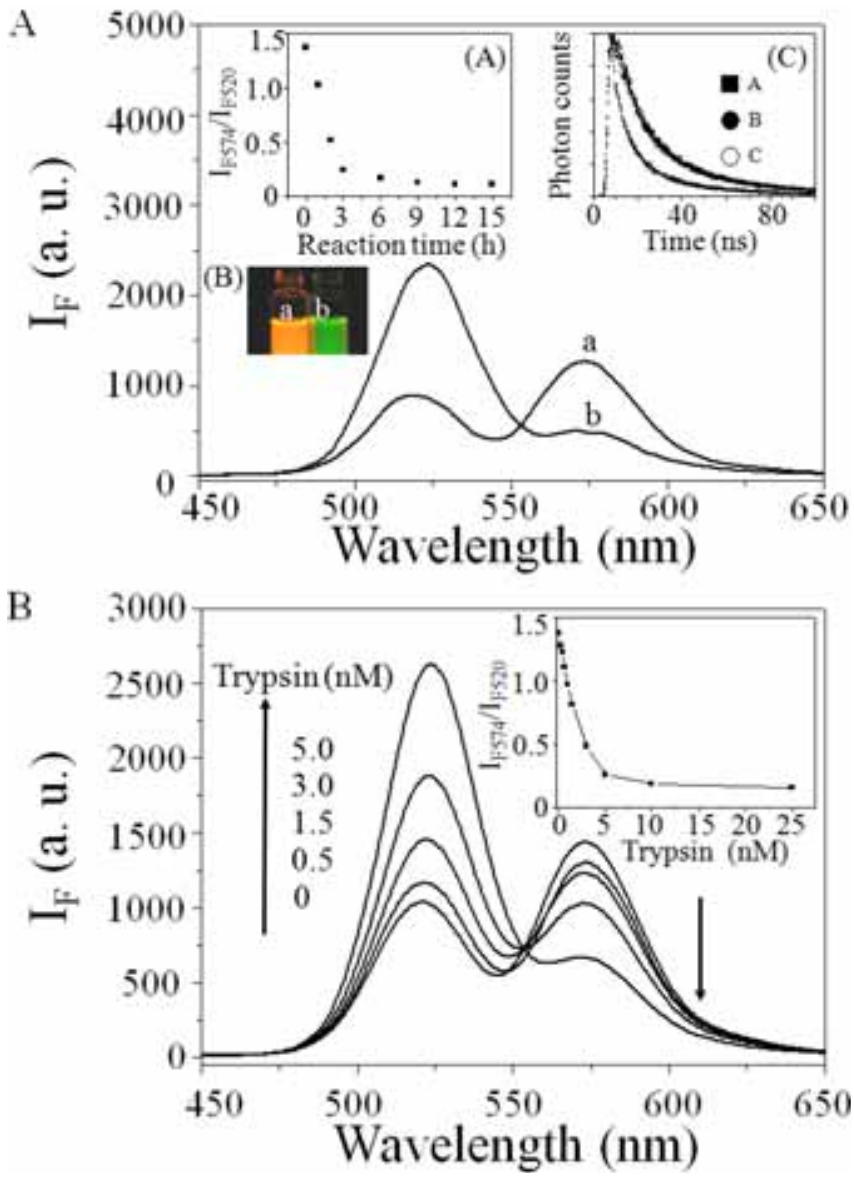

Fig. (3). (A) Fluorescence spectra of (a) CdTe-BSA-RITC QDs (30 $\mathrm{nM})$ and (b) a mixture of CdTe-BSA-RITC QDs (30 nM) and Try $(5 \mathrm{nM})$ after their reaction for $3 \mathrm{~h}$. Inset A: Plot of $I_{\mathrm{F} 574} / I_{\mathrm{F} 520}$ versus reaction time at $37^{\circ} \mathrm{C}$; inset $\mathrm{B}$ : colors before and after Try $(5 \mathrm{nM})$ digestion of CdTe-BSA-RITC QDs $(30 \mathrm{nM})$; inset C: lifetime decays fitted with an exponential decay for (A) CdTe-BSA QDs (30 $\mathrm{nM})$ and (B,C) CdTe-BSA-RITC QDs $(30 \mathrm{nM})$ before and after Try digestion. Excitation wavelength: $350 \mathrm{~nm}$. (B) Fluorescence response of CdTe-BSA-RITC QDs $(30 \mathrm{nM})$ upon addition of Try $(0,0.5,1.5,3.0$, and $5.0 \mathrm{nM})$. Inset: Plot of $I_{\mathrm{F} 574} / I_{\mathrm{F} 520}$ versus Try concentration. Other conditions are the same as those described in Fig. (2).

and an LOD of $510 \mathrm{pM}$ for TI (Fig. 5A). This result suggests that our approach is selective for TI. Owing to high specific- 
ity of Try toward TI and low concentrations of other possible

proteins like BSA in urine, we expect the interference from other proteins should be negligible. Next, we used urine samples to determine the practicality of our present approach. Urine samples from adult males in our research group were spiked with TI and subjected to centrifugal filtration through a membrane (cutoff: $3 \mathrm{kDa}$ ) to remove small molecules such as cysteine, which might have interfered with the assay through thiol-induced aggregation, and catecholamines and peptides to decrease the fluorescence background somewhat. To achieve optimum enzyme activity, the collected urine materials were resuspended in phosphate buffer (5 mM, pH 7.4). As indicated in Fig. 5B, a linear correlation $\left(\mathrm{R}^{2}=0.98\right)$ existed between the $I_{\mathrm{F} 574} / I_{\mathrm{F} 520}$ ratios and the concentration $(0.30-5.0 \mathrm{nM})$ of TI spiked in one of the urine samples. The percentage recoveries of TI $(1.0 \mathrm{nM})$ from 25 urine samples were $95-110 \%$, highlighting the selectivity of this approach. The percentage recoveries were higher than $100 \%$ in a majority of cases (16 out of 25 measurements), mainly because the urine samples contained low-molecular-weight TIs that have structures and biologically activities that differ from those of the standard TI [19]. Because the two low-molecular-weight TI standards were not accessible to this laboratory, we did not determine their concentrations in the urine samples.

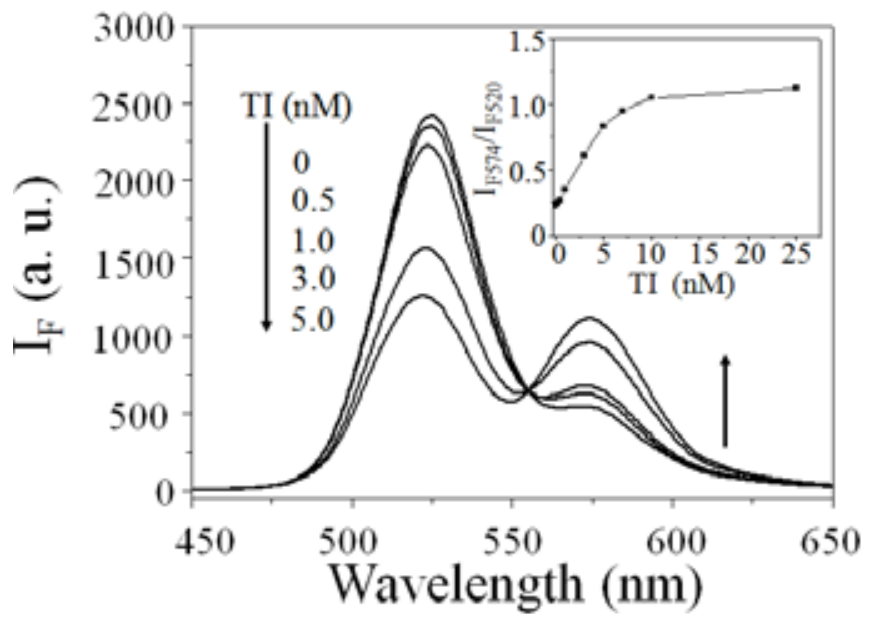

Fig. (4). Fluorescence response of CdTe-BSA-RITC QDs upon addition of TI $(0,0.5,1.0,3.0$, and $5.0 \mathrm{nM})$ at a constant Try concentration $(10.0 \mathrm{nM})$. Inset: Plot of $I_{\mathrm{F} 574} / I_{\mathrm{F} 520}$ versus TI concentration. Other conditions are the same as those described in Fig. (2).

\section{CONCLUSIONS}

We have demonstrated a new homogeneous assay for the detection of both Try and TI through FRET using CdTe QDs and BSA-RITC. For the first time, we found that the preparation temperature for the CdTe-BSA-RITC QDs is an important parameter for determining the FRET efficiency and QY of CdTe QDs. We suggest that the effect of the temperature is related to changes in the BSA conformation. In the presence of Try, the CdTe-BSA-RITC QD probe provided a linear response from 0.30 to $5.0 \mathrm{nM}$ for TI, with an LOD of $250 \mathrm{pM}$. The advantages of this new probe include high sensitivity, low cost, minimal matrix interference, and simplicity. Our results suggest that this approach holds great potential for screening TI in a variety of biological samples. For example, screening urinary TIs that contain Kazal- and $\mathrm{Ku}$ nitz-type inhibitors in biological fluids is important for the diagnosis of ovarian, bladder, kidney, and renal cancers [1921]. We also believe that this approach can serve as a foundation for the development of practical nanosensors for the detection of other important biomarkers when using different pairs of proteases and proteins/peptides.
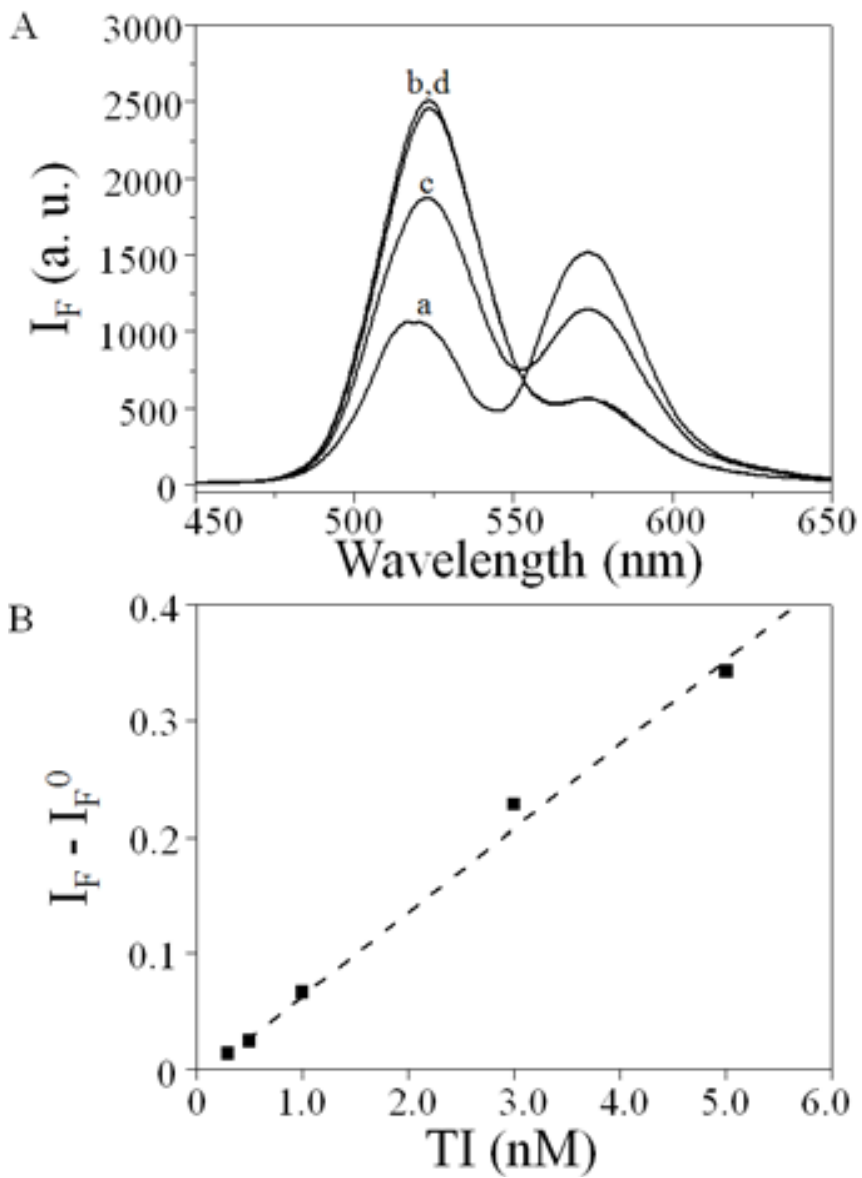

Fig. (5). (A) Fluorescence spectra of CdTe-BSA-RITC QD solutions in the (a) absence and (b) presence of Try $(10.0 \mathrm{nM})$, (c) in the presence of Try $(10.0 \mathrm{nM})$, TI $(3.0 \mathrm{nM})$, and excess BSA (1.0 $\mu \mathrm{M})$, and (d) in the presence of Try $(10.0 \mathrm{nM})$ and excess BSA (1.0 $\mu \mathrm{M})$. (B) Fluorescence response of CdTe-BSA-RITC QDs upon spiking TI into a urine sample. Plot of $\left(I_{\mathrm{F}}-I_{\mathrm{F}}{ }^{0}\right)$ versus the TI concentration, where $I_{\mathrm{F}}$ and $I_{\mathrm{F}}{ }^{0}$ represent the ratios of fluorescence intensities at 574 and $520 \mathrm{~nm}$ in the presence and absence of TI, respectively. Other conditions are the same as those described in Fig. (2).

\section{ACKNOWLEDGEMENT}

This study was supported by the National Science Council of Taiwan under contract NSC 95-2113-M-002-026MY3.

\section{REFERENCES}

[1] Bruchez, M. Jr.; Moronne, M.; Gin, P.; Weiss, S.; Alivisatos, A.P. Science, 1998, 281, 2013-2016.

[2] Chan, W. C. W.; Nie, S. M. Science, 1998, 281, 2016-2018.

[3] Tran, P. T.; Goldman, E. R.; Anderson, G. P.; Mauro, J. M.; Mattoussi, H. Phys. Status Solidi B, 2002, 229, 427-432.

[4] Lin, Y. W.; Hsieh, M. M.; Liu, C. P.; Chang, H. T. Langmuir, 2005, 21, 728-734. 
[5] Jaiswal, J. K.; Mattoussi, H.; Mauro, J. M.; Simon, S. M. Nature Biotechnol., 2003, 21, 47-51.

[6] Lingerfelt, B. M.; Mattoussi, H.; Goldman, E. R.; Mauro, J. M.; Anderson, G. P. Anal. Chem., 2003, 75, 4043-4049.

[7] Goldman, E. R.; Clapp, A. R.; Anderson, G. P.; Uyeda, H. T.; Mauro, J. M.; Medintz, I. L.; Mattoussi, H. Anal. Chem., 2004, 76, 684-688.

[8] Kagan, C. R.; Murray, C. B.; Nirmal, M.; Bawendi, M. G. Phys. Rev. Lett., 1996, 76, 1517-1520.

[9] Mamedova, N. N.; Kotov, N. A. Nano Lett. 2001, 1, 281-286.

[10] Willard, D. M.; Carillo, L. L.; Jung, J.; Orden, A. V. Nano Lett., 2001, 1, 469-474.

[11] Clapp, A. R.; Medintz, I. L.; Mauro, J. M.; Fisher, B.R.; Bawendi, M. G.; Mattoussi, H. J. Am. Chem. Soc., 2004, 126, 301-310.

[12] Wang, S.; Mamedova, N.; Kotov, N. A.; Chen, W.; Studer, J. Nano Lett., 2002, 2, 817-822.

[13] Medintz, I. L.; Clapp, A. R.; Mattoussi, H.; Goldman, E. R.; Mauro, J. M. Nat. Mater., 2003, 2, 630-638.

[14] Chang, E.; Miller, J. S.; Sun, J.; Yu, W. W.; Colvin, V. L.; Drezek, R.; West, J. L. Biochem. Biophys. Res. Commun., 2005, 334, 13171321.

[15] Xu, C.; Xing, B.; Rao, J. Biochem. Biophys. Res. Commun., 2006, 344, 931-935.

[16] Shi, L.; Paoli, V. D.; Rosenzweig, N.; Rosenzweig, Z. J. Am. Chem. Soc., 2006, 128, 10378-10379. (b) Shi, L.; Rosenzweig, N.; Rosenzweig, Z. Anal. Chem. 2007, 79, 208-214.

[17] Gerion, D.; Pinaud, F.; Williams, S. C.; Parak, W. J.; Zanchet, D.; Weiss, S.; Alivisatos, A. P. J. Phys. Chem. B, 2001, 105, 88618871.

[18] Pinaud, F.; King, D.; Moore, H. P.; Weiss, S. J. Am. Chem. Soc., 2004, 126, 6115-6123.

[19] Sbrana, E.; Spinetti, M.; Secco, F.; Raspi, G. Polyhedron, 2002, 21, 1475-1479.
[20] Liony, C ; Sesbue, R.; Manchon, N. D.; Bercoft, E.; Delzant, G.; Martin, J. P. Presse Med., 1991, 20, 203-206.

[21] Sparro, G.; Bnaiuto, S.; Galdenzi, G.; HIcuteri, A. M.; Angeletti, M.; Lupidi, G. Dis. Markers, 1996, 13, 31-41.

[22] Huhtala, M. L.; Stenman, U. H. Int. J. Cancer, 1983, 31, 711-714.

[23] Huhtala, M. L. Hoppe-Seyler's Z. Physiol. Chem., 1984, 365, 819 825.

[24] Peters, T. Jr. All About Albumin. Biochemistry, Genetics, and Medical Applications; Academic Press: San Diego, 1995.

[25] Hanaki, K.; Momo, A.; Oku, T.; Komoto, A.; Maenosono, S.; Yamaguchi, Y.; Yamamotob, K. Biochem. Biophys. Res. Commun., 2003, 302, 496-501.

[26] Sakiyama, T.; Toyomasu, T.; Nagata, A.; Imamura, K.; Nakanishi, K.; Takahashi, T.; Nagai, T. J. Chem. Eng. Jpn., 1998, 31, 208-213.

[27] Chang, H. T.; Yeung, E. S. J. Chromatogr. B 1995, 669, 113-123.

[28] Georges, J.; Arnaud, N.; Parise, L. Appl. Spectrosc., 1996, 50, 1505-1511.

[29] Gao, M. Y.; Kirstein, S.; Möhwald, H.; Rogach, A. L.; Kornowski, A.; Eychmuller, A.; Weller, H. J. Phys. Chem. B, 1998, 102, 83608363 .

[30] Zhang, H.; Zhou, Z.; Yang, B. J. Phys. Chem. B 2003, 107, 8-13.

[31] Yang, Q.; Tang, K.; Wang, C.; Qian, Y.; Zhang, S. J. Phys. Chem. $B, \mathbf{2 0 0 2}, 106,9227-9230$.

[32] Lin, Y. W.; Tseng, W. L.; Chang, H. T. Adv. Mater., 2006, 18, 1381-1386.

[33] Tehei, M.; Madern, D.; Pfister, C.; Zaccai, G. Proc. Natl. Acad. Sci. U.S.A., 2001, 98, 14356-14361.

[34] Vihinen-Ranta, M.; Kakkola, L.; Kalela, A.; Vilja, P., Vuento, M. Eur. J. Biochem., 1997, 250, 389-394.

[35] Lakowicz, J. R. Principles of Fluorescence Spectroscopy, 2nd ed.; Kluwer Academic: New York, 1999.

[36] Turpeinen, U.; Koivunen, E.; Stenman, U. Biochem. J., 1988, 254, 911-914.

[37] Bellby, J. P.; O'Leary, B. A. Clin. Chem., 1990, 36, 565-567. 